\title{
Molecular Cloning and Gene Expression of Canine Apoptosis Inhibitor of Macrophage
}

\author{
Shintaro TOMURA ${ }^{1)}$, Mona UCHIDA ${ }^{1)}$, Tomohiro YONEZAWA ${ }^{1) *}$, Masato KOBAYASHI ${ }^{2)}$, Makoto BONKOBARA ${ }^{2)}$, \\ Satoko ARAI $^{3)}$, Toru MIYAZAKI ${ }^{3,4)}$, Satoshi TAMAHARA ${ }^{1)}$ and Naoaki MATSUKI ${ }^{1)}$ \\ ${ }^{1)}$ Laboratory of Veterinary Clinical Pathobiology, Department of Veterinary Medical Sciences, Graduate School of Agricultural and Life \\ Sciences, The University of Tokyo, 1-1-1 Yayoi, Bunkyo-ku, Tokyo 113-8657, Japan \\ 2) Department of Veterinary Clinical Pathology, Nippon Veterinary and Life Science University, 1-7-1 Kyonan-cho, Musashino-shi, Tokyo \\ 180-8602, Japan \\ ${ }^{3)}$ Laboratory of Molecular Biomedicine for Pathogenesis, Center for Disease Biology and Integrative Medicine, Faculty of Medicine, \\ The University of Tokyo, 7-3-1 Hongo Bunkyo-ku, Tokyo 113-0033, Japan \\ 4) CREST, Japan Science and Technology Agency, Hongo Bunkyo-ku, Tokyo 113-0033, Japan
}

(Received 27 March 2014/Accepted 11 August 2014/Published online in J-STAGE 1 September 2014)

ABSTRACT. Apoptosis inhibitor of macrophage (AIM) plays roles in survival of macrophages. In this study, we cloned canine AIM cDNA and observed its transcriptional expression levels in various tissues. The coding sequence of canine AIM was 1,023 bp encoding 340 amino acid residues, which had around $65 \%$ homology with those of the human, mouse and rat. Transcriptional expression of AIM was observed in the spleen, lung, liver and lymph node, which confirmed the expression of canine AIM in tissue macrophages. Moreover, AIM was highly expressed in one of the canine histiocytic sarcoma cell lines. CD36, the receptor of AIM, was also expressed in various tissues and these cell lines. These findings are useful to reveal the actual functions of canine AIM.

KEY WORDS: apoptosis inhibitor of macrophage (AIM), canine, CD36, CD5L, scavenger receptor cysteine-rich (SRCR) superfamily

doi: 10.1292/jvms.14-0166; J. Vet. Med. Sci. 76(12): 1641-1645, 2014

Apoptosis inhibitor of macrophage (AIM) is a member of the scavenger receptor cysteine-rich (SRCR) superfamily. The SRCR superfamily is characterized by unique cysteine-rich domains, which was initially discovered in type I macrophage scavenger receptor $[5,10]$. Although the SRCR domain is highly conserved among members of the superfamily, each member appears to have different functions [17, 18]. AIM was initially identified in humans and mice as a protein that is produced by mature tissue macrophages and supports cell survival against various apoptosisinducing stimuli $[7,11,14]$. In other reports, AIM is secreted into circulation and effects on survival of various immune cells including macrophages themselves, B lymphocytes and natural killer T cells $[6,8,9,13,20]$. Based on these functions of AIM, AIM signal could be related to tumorigenic transformation of macrophages, such as histiocytic sarcoma.

AIM is also discussed as a key molecule on diabetes, metabolic syndrome and obesity. Progression of obesity leads to infiltration of inflammatory macrophages into the adipose tissue which triggers insulin resistance and metabolic syndrome $[16,19]$. AIM is highly secreted in obese

*Correspondence to: Yonezawa, T., Laboratory of Veterinary Clinical Pathobiology, Department of Veterinary Medical Sciences, Graduate School of Agricultural and Life Sciences, The University of Tokyo, 1-1-1 Yayoi, Bunkyo-ku, Tokyo 113-8657, Japan. e-mail: ayone@mail.ecc.u-tokyo.ac.jp

(C)2014 The Japanese Society of Veterinary Science

This is an open-access article distributed under the terms of the Creative Commons Attribution Non-Commercial No Derivatives (by-nc-nd) License $<$ http://creativecommons.org/licenses/by-nc-nd/3.0/>. animals and initiates macrophage recruitment into adipose tissue, which is followed by insulin resistance $[2,12]$. Moreover, AIM has high binding affinity to CD36, and then, the complex causes lipolysis via suppression of cytosolic fatty acid synthase activity $[4,12]$. Thus, suppression of AIM may be therapeutically applicable for the prevention of obesityrelated lipid metabolism disorders. In the present study, we performed molecular cloning of canine AIM gene and observed its transcriptional expression levels in various normal tissues and cell lines of histiocytic sarcoma.

To determine the coding sequence (CDS) of canine AIM, a frozen spleen tissue specimen from a healthy adult Beagle dog, which was kindly gifted from Professor Tsujimoto, the University of Tokyo, was used. The tissue specimen was stored at $-80^{\circ} \mathrm{C}$ until use. Total RNA of the tissue specimen was prepared using RNeasy Mini Kit (QIAGEN, Hilden, Germany). After treatment with DNase I, the total RNA was converted into cDNA using a SuperScript III First-Strand Synthesis System for RT-PCR (Invitrogen, Carlsbad, CA, U.S.A.). To clone the CDS of canine AIM gene, primer sets were designed according to a predicted sequence of canine AIM gene (GenBank accession no. XM_005622660, Table 1). Using primers P1 and P4, the canine AIM cDNA was amplified from the spleen cDNA by polymerase chain reaction (PCR) with AmpliTaq Gold (Applied Biosystems, Forster City, CA, U.S.A.). Conditions for PCR cycles were as follows: preheating at $95^{\circ} \mathrm{C}$ for $9 \mathrm{~min} ; 35$ cycles at $94^{\circ} \mathrm{C}$ for $30 \mathrm{sec}, 63^{\circ} \mathrm{C}$ for $30 \mathrm{sec}$ and $72^{\circ} \mathrm{C}$ for $2 \mathrm{~min}$. PCR product was cloned into the pCR II-TOPO vector using a TA Cloning kit (Invitrogen), followed by transformation of Escherichia coli competent cells (Invitrogen). Plasmid DNAs were ex- 
Table 1. Sequences of oligonucleotide primers used for gene cloning of canine AIM

\begin{tabular}{clc}
\hline Primers & \multicolumn{1}{c}{ Sequence $\left(5^{\prime}-3^{\prime}\right)$} & Positions \\
\hline P1 & Forward GTC AGC ATC TCC AGC AGC CTG & $-25-5$ \\
P2 & Forward GAA CTT TGC AGC TGC CAA GGT G & $477-498$ \\
P3 & Reverse CAT TTC CGG GTC AGT ATG GCC & $545-525$ \\
P4 & Reverse GGT CAG CTC AGG CAT CAG GTA G & $1051-1030$ \\
\hline
\end{tabular}

tracted from bacterial cultures grown in LB agar medium using a QIAprep Spin Miniprep kit (QIAGEN). For DNA sequencing, PCR was performed using several primer sets (Table 1, P1-P3, P2-P3 and P2-P4). PCR products were sequenced using a BigDye Terminator v3.1 Cycle Sequencing Kit (Applied Biosystems) with an Applied Biosystems $3130 \times 1$ Genetic Analyzer (Applied Biosystems). Then, the CDS of canine AIM cDNA was determined using Sequence Scanner v1.0 (Applied Biosystems), followed by converting into amino acids sequence and compared to nucleotide/ amino acids sequence of the CDS of AIM of the human (accession no. NM_005894), mouse (NM_009690) and rat (NM_001025685), using CLC Sequence Viewer 6 (QIAGEN) and L-ALIGN (http://embnet.vital-it.ch/software/ LALIGN form.html).

The $\bar{C} \bar{D}$ S of canine AIM was 1,023 bp encoding 340 amino acid residues (Fig. 1). It has been registered in DDBJ under accession no. AB_915633. It was almost consistent with predicted CDS of canine AIM (99.8\%, 1,021 of 1,023 $\mathrm{bp})$, however, there were two single amino-acid replacements (F7L and R138C). Canine AIM included amino acid sequences of a presumed signal peptide and three SRCR domains. AIM is divided into reported to have two types among animal species. AIM of humans, mice and rats contains three SRCR domains, while bovine and porcine AIM contains more than three SRCR domains (bovine: accession no. NM_001102119 and porcine: NM_001243468). Thus, canine AIM was similar to human, mouse and rat AIM. The amino acid sequence of canine AIM was shown to have $66.2 \%, 61.0 \%$ and $64.5 \%$ of similarity with those of human, mouse and rat AIM, respectively (Fig. 2). We found eleven

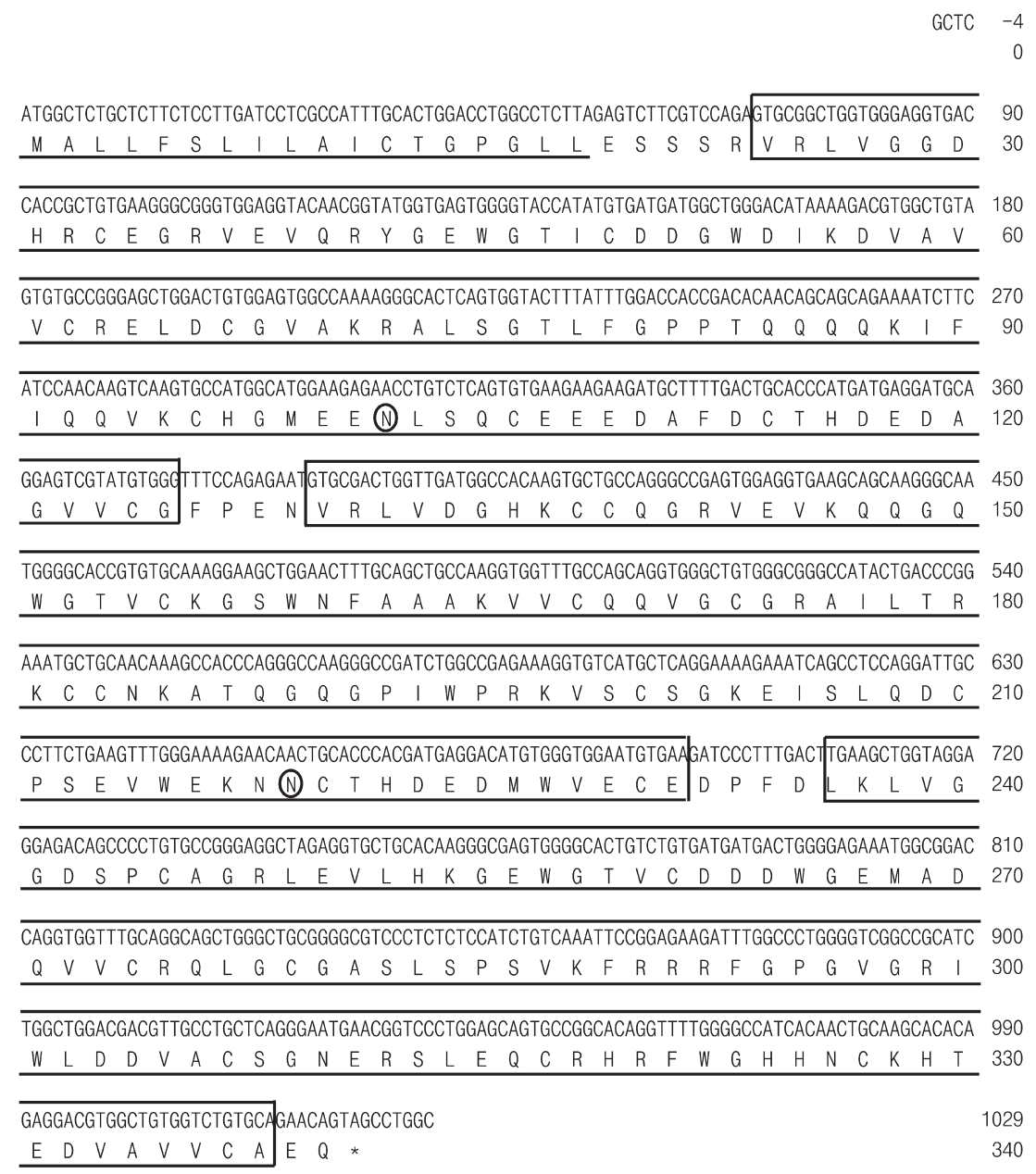

Fig. 1. Nucleotide and deduced amino acid sequences of canine AIM (accession number: AB_915633). The CDS of canine AIM was composed of 1,023 bp encoding 340 amino acids residues. The predicted signal peptide of canine AIM is marked by an underline. The three presumed SRCR domains are boxed with solid lines. Predicted N-linked glycosylation sites were shown as circles. 


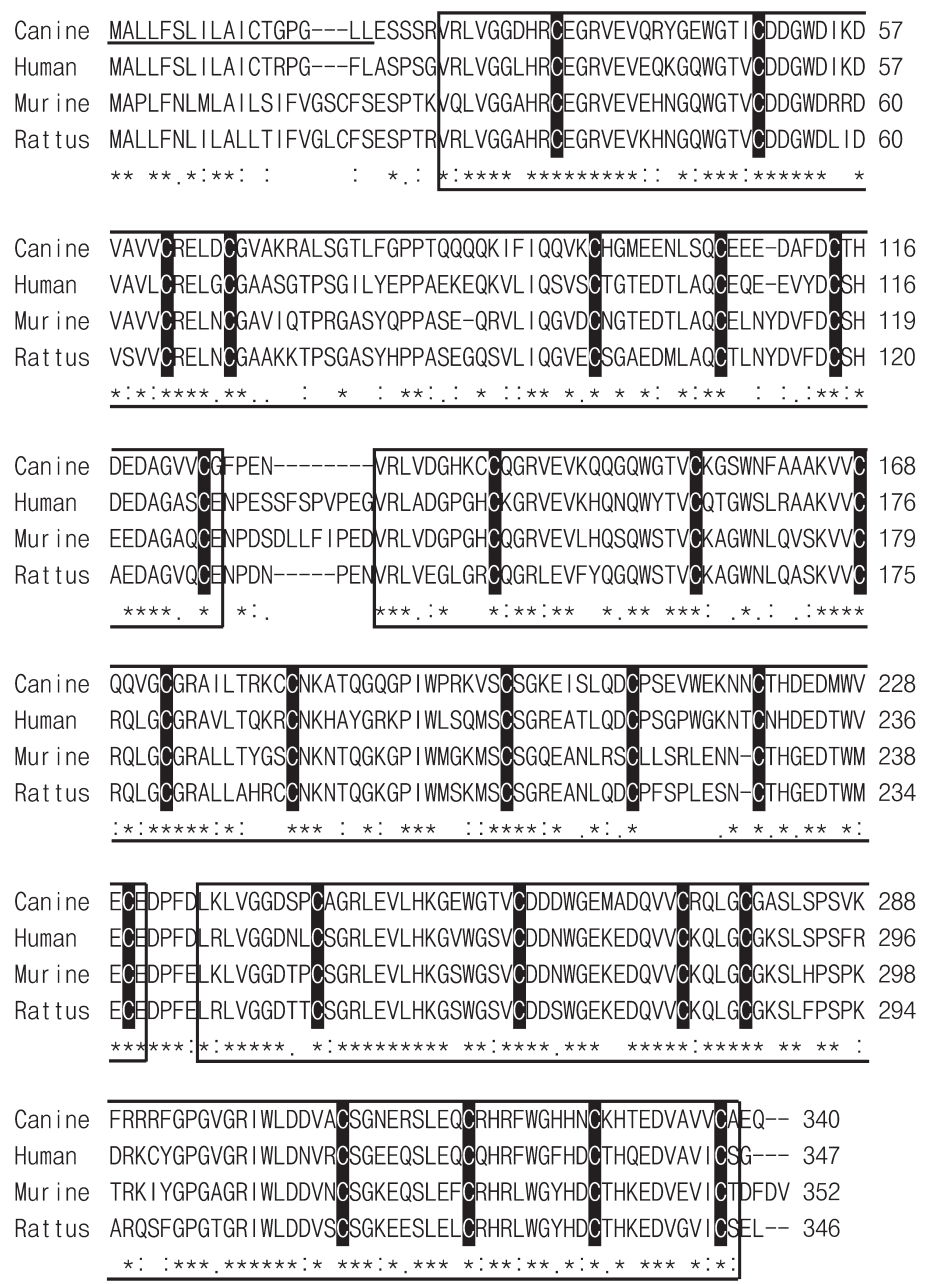

Fig. 2. Alignment of the deduced amino acid sequence of the CDS of canine AIM with those of human, mouse and rat homologs. The deduced amino acid sequence of canine AIM cDNA cloned in this study was shown to have $66.2 \%, 61.0 \%$ and $64.5 \%$ similarity with those of the human, mouse and rat counterparts, respectively. Asterisks indicate identical amino acids. Colons and periods indicate strong and weak conservation of similar amino acid properties. The predicted signal peptide of canine AIM is marked by an underline. Cysteine residues are shown on a black background. The three presumed SRCR domains are boxed with solid lines.

disulfide bond sites in canine AIM, which were perfectly conserved compared to those of human, mouse and rat AIM.

The transcriptional expression ratios of canine AIM in various tissues were detected (Fig. 3). Frozen tissues from six healthy adult Beagle dogs were used. They were kindly gifted from Professor Sasaki, the University of Tokyo. RNA samples from the cerebrum, thyroid gland, lung, heart, liver, pancreas, stomach, small intestine, colon, kidney, spleen and lymph node were isolated and converted to cDNA. Transcriptional expression ratios of canine AIM, CD36 and glyceraldehyde-3 phosphate dehydrogenase (GAPDH) as an internal control were quantified by StepOnePlus Real-Time PCR system (Applied Biosystems) using a commercial kit (Thunderbird SYBR qPCR Mix, Toyobo, Osaka, Japan). The sequences of the primer pairs used for q-PCR are shown in Table 2. A standard curves method was employed for quantification of PCR products. Conditions for q-PCR cycles were as follows: preheating at $95^{\circ} \mathrm{C}$ for $10 \mathrm{~min} ; 40$ cycles at $95^{\circ} \mathrm{C}$ for $15 \mathrm{sec}$ and $60^{\circ} \mathrm{C}$ for $1 \mathrm{~min}$. All samples were examined in triplicate, and each of samples had only a single peak in the melting curve.

Among tissues tested in this study, substantial mRNA expression of canine AIM was observed in lung, thyroid gland, liver, spleen and lymph node (Fig. 3). Especially, AIM gene was tremendously highly expressed in the spleen. The other tissues, such as cerebrum, pancreas, small intestine and colon, showed very little AIM gene expression. In previous reports of mice, AIM mRNA is expressed in mature tissue macrophages in peritoneal exudate cells, spleen and expressed in fetal liver, lung, bone marrow and lymph node [7, 14]. Our results in this study are consisted with these reports. Although there is no direct evidence that macrophages themselves express AIM, transcriptional levels of canine AIM could be dependent on distribution of tissue macrophages.

CD36 is one of the binding proteins for AIM and involved in AIM-related lipid metabolism [4]. In this study, expres- 
Table 2. Sequences of oligonucleotide primers used for q-PCR

\begin{tabular}{clcc}
\hline Primer set & \multicolumn{1}{c}{ Sequence $\left(5^{\prime}-3^{\prime}\right)$} & Positions & Accession number \\
\hline AIM & & & \\
$\begin{array}{l}\text { Forward } \\
\text { Reverse }\end{array}$ & TCC AGA GAA TGT GCG ACT GG & $378-488$ & XM_005622660 \\
CD36 & & & \\
$\quad \begin{array}{l}\text { Forward } \\
\text { Reverse }\end{array}$ & AAG GAA GTT GTA CTT GAA GAA GGT & $118-224$ & GU_108578 \\
$\begin{array}{c}\text { GAPDH } \\
\text { Forward } \\
\text { Reverse }\end{array}$ & GCT GCC AAA TAT GAC GAC ATC A & $748-822$ & NM_001003142 \\
\hline
\end{tabular}
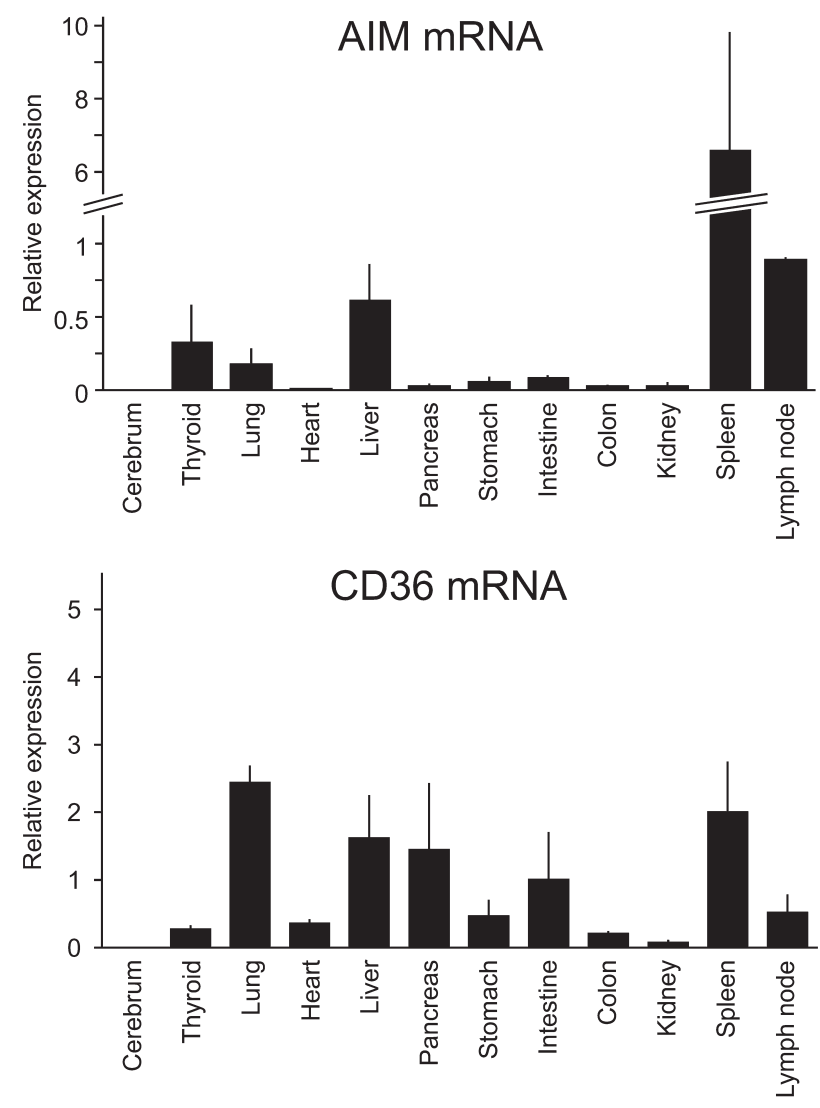

Fig. 3. Expression levels of AIM and CD36 mRNA in five healthy adult dog tissues. These gene expression levels were normalized to GAPDH. The columns and error bars represent the means and their standard errors.

sion ratios of CD36 mRNA in various tissues were also observed (Fig. 3). Although the expression quantities were quite different among tissues, all tissues except the cerebrum possessed had substantial CD36 mRNA. The high levels of CD36 expression were observed in the lung and spleen, whereas the lower levels were found in the thyroid gland, heart, stomach, kidney, pancreas, colon and lymph node. Thus, the targets of canine AIM could be also wide-spread like those of mouse and human AIM [4, 12, 20], which could have multifunctions for cell survival and diabetic metabo-

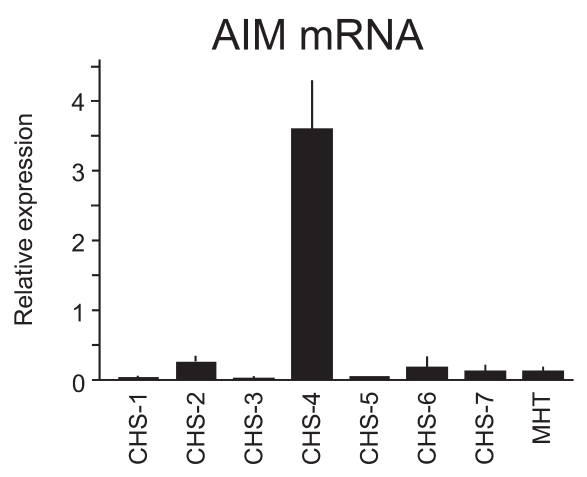

\section{CD36 mRNA}

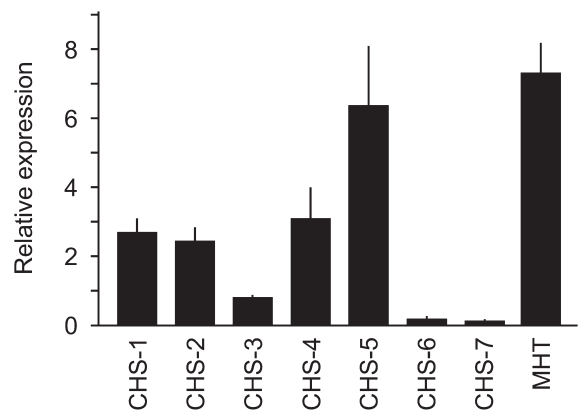

Fig. 4. Expression levels of AIM and CD36 mRNA in eight histiocytic sarcoma cell lines. These gene expression levels were normalized to GAPDH. The columns and error bars represent the means and their standard errors.

lisms. Future studies are needed to reveal the actual functions of AIM in the dog.

Interestingly, we observed AIM expression in the thyroid gland. Based on the histological aspect, the thyroid gland should contain very few tissue macrophages. To our knowledge, AIM expression of thyroid gland has not been investigated in any other previous reports. Although AIM is believed to be specifically expressed in macrophages [7, 14], it might be expressed in other cell types, such as thyroid glands. As CD36 mRNA was also detected in the thyroid gland in this study, it is implicated that AIM could be also 
functional in the thyroid gland. However, since AIM gene expression in the thyroid gland was variable, it can't be completely denied that some of them had the latent thyroiditis.

Canine histiocytic sarcoma is a tumor derived from macrophages, dendritic cells, monocytes and Langerhans cells $[1,15]$. In this study, expression ratios of AIM and CD36 mRNA in several histiocytic sarcoma cell lines were observed. The cell lines were established by Dr. Azakami [3]. RNA samples were extracted from three different passages of each cell line, and the quantities were measured using qPCR. As shown in Fig. 4, AIM mRNA was highly expressed in one cell line and CD 36 was highly expressed in six cell lines, while both of them were low in two out of eight cell lines. These results may attribute to the facts that some histiocytic sarcoma cells are derived from other cells than macrophages $[1,15]$ and there could be other reasons in tumorigenesis of histiocytic sarcoma. Comparisons of AIM expression levels in in vivo primary tumor tissues with other healthy organs are needed in next studies. Nevertheless, it is suggested that AIM expression could be altered at least in some of histiocytic sarcoma cell lines and these cell lines are good models to reveal the mechanisms of tumorigenesis related to AIM.

In conclusion, we cloned the canine AIM mRNA sequence and detected distribution of transcriptional expression of AIM and CD36 in dogs. Canine AIM has a signal peptide and three SRCR domains, conserved compared to human, mouse and rat AIM. Canine AIM mRNA was expressed highly in spleen and other organs which have tissue macrophages, such as lung, liver, lymph nodes and histiocytic sarcoma. CD36 was also expressed in various tissues and histiocytic sarcoma, indicating that canine AIM could have many targets and multifunctions.

\section{REFERENCES}

1. Affolter, V. K. and Moore, P. F. 2002. Localized and disseminated histiocytic sarcoma of dendritic cell origin in dogs. Vet. Pathol. 39: 74-83. [Medline] [CrossRef]

2. Arai, S., Shelton, J. M., Chen, M., Bradley, M. N., Castrillo, A., Bookout, A. L., Mak, P. A., Edwards, P. A., Mangelsdorf, D. J., Tontonoz, P. and Miyazaki, T. 2005. A role for the apoptosis inhibitory factor AIM/Spalpha/Api6 in atherosclerosis development. Cell Metab. 1: 201-213. [Medline] [CrossRef]

3. Azakami, D., Bonkobara, M., Washizu, T., Iida, A., Kondo, M., Kato, R., Niikura, Y., Iwaki, S., Tamahara, S., Matsuki, N. and Ono, K. 2006. Establishment and biological characterization of canine histiocytic sarcoma cell lines. J. Vet. Med. Sci. 68: 1343-1346. [Medline] [CrossRef]

4. Febbraio, M., Podrez, E. A., Smith, J. D., Hajjar, D. P., Hazen, S. L., Hoff, H. F., Sharma, K. and Silverstein, R. L. 2000. Targeted disruption of the class $\mathrm{B}$ scavenger receptor $\mathrm{CD} 36$ protects against atherosclerotic lesion development in mice. J. Clin. Invest. 105: 1049-1056. [Medline] [CrossRef]

5. Freeman, M., Ashkenas, J., Rees, D. J., Kingsley, D. M., Copeland, N. G., Jenkins, N. A. and Krieger, M. 1990. An ancient, highly conserved family of cysteine-rich protein domains revealed by cloning type I and type II murine macrophage scavenger receptors. Proc. Natl. Acad. Sci. U.S.A. 87: 8810-8814. [Medline] [CrossRef]
6. Gangadharan, B., Antrobus, R., Dwek, R. A. and Zitzmann, N. 2007. Novel serum biomarker candidates for liver fibrosis in hepatitis C patients. Clin. Chem. 53: 1792-1799. [Medline] [CrossRef]

7. Gebe, J. A., Kiener, P. A., Ring, H. Z., Li, X., Francke, U. and Aruffo, A. 1997. Molecular cloning, mapping to human chromosome 1 q21-q23, and cell binding characteristics of Spalpha, a new member of the scavenger receptor cysteine-rich (SRCR) family of proteins. J. Biol. Chem. 272: 6151-6158. [Medline] [CrossRef]

8. Gray, J., Chattopadhyay, D., Beale, G. S., Patman, G. L., Miele, L., King, B. P., Stewart, S., Hudson, M., Day, C. P., Manas, D. M. and Reeves, H. L. 2009. A proteomic strategy to identify novel serum biomarkers for liver cirrhosis and hepatocellular cancer in individuals with fatty liver disease. BMC Cancer 9: 271. [Medline] [CrossRef]

9. Kim, W. K., Hwang, H. R., Kim, H., Lee, P. Y., In, Y. J., Ryu, H. Y., Park, S. G., Bae, K. H. and Lee, S. C. 2008. Glycoproteomic analysis of plasma from patients with atopic dermatitis: CD5L and ApoE as potential biomarkers. Exp. Mol. Med. 40: 677-685. [Medline] [CrossRef]

10. Krieger, M. 1992. Molecular flypaper and atherosclerosis: structure of the macrophage scavenger receptor. Trends Biochem. Sci. 17: 141-146. [Medline] [CrossRef]

11. Kurokawa, J., Arai, S., Nakashima, K., Nagano, H., Nishijima, A., Miyata, K., Ose, R., Mori, M., Kubota, N., Kadowaki, T., Oike, Y., Koga, H., Febbraio, M., Iwanaga, T. and Miyazaki, T. 2010. Macrophage-derived AIM is endocytosed into adipocytes and decreases lipid droplets via inhibition of fatty acid synthase activity. Cell Metab. 11: 479-492. [Medline] [CrossRef]

12. Kurokawa, J., Nagano, H., Ohara, O., Kubota, N., Kadowaki, T., Arai, S. and Miyazaki, T. 2011. Apoptosis inhibitor of macrophage (AIM) is required for obesity-associated recruitment of inflammatory macrophages into adipose tissue. Proc. Natl. Acad. Sci. U.S.A. 108: 12072-12077. [Medline] [CrossRef]

13. Kuwata, K., Watanabe, H., Jiang, S. Y., Yamamoto, T., Tomiyama-Miyaji, C., Abo, T., Miyazaki, T. and Naito, M. 2003. AIM inhibits apoptosis of T cells and NKT cells in Corynebacteriuminduced granuloma formation in mice. Am. J. Pathol. 162: 837-847. [Medline] [CrossRef]

14. Miyazaki, T., Hirokami, Y., Matsuhashi, N., Takatsuka, H. and Naito, M. 1999. Increased susceptibility of thymocytes to apoptosis in mice lacking AIM, a novel murine macrophage-derived soluble factor belonging to the scavenger receptor cysteine-rich domain superfamily. J. Exp. Med. 189: 413-422. [Medline] [CrossRef]

15. Moore, P. F., Affolter, V. K. and Vernau, W. 2006. Canine hemophagocytic histiocytic sarcoma: a proliferative disorder of CD11d+ macrophages. Vet. Pathol. 43: 632-645. [Medline] [CrossRef]

16. Neels, J. G. and Olefsky, J. M. 2006. Inflamed fat: what starts the fire? J. Clin. Invest. 116: 33-35. [Medline] [CrossRef]

17. Resnick, D., Chatterton, J. E., Schwartz, K., Slayter, H. and Krieger, M. 1996. Structures of class A macrophage scavenger receptors. Electron microscopic study of flexible, multidomain, fibrous proteins and determination of the disulfide bond pattern of the scavenger receptor cysteine-rich domain. J. Biol. Chem. 271: 26924-26930. [Medline] [CrossRef]

18. Resnick, D., Pearson, A. and Krieger, M. 1994. The SRCR superfamily: a family reminiscent of the Ig superfamily. Trends Biochem. Sci. 19: 5-8. [Medline] [CrossRef]

19. Shoelson, S. E., Lee, J. and Goldfine, A. B. 2006. Inflammation and insulin resistance. J. Clin. Invest. 116: 1793-1801. [Medline] [CrossRef]

20. Yusa, S., Ohnishi, S., Onodera, T. and Miyazaki, T. 1999. AIM, a murine apoptosis inhibitory factor, induces strong and sustained growth inhibition of B lymphocytes in combination with TGFbeta1. Eur. J. Immunol. 29: 1086-1093. [Medline] [CrossRef] 